\title{
Consumption of Ferulic and $p$-Hydroxybenzoic Acids by Soybean Root Tips
}

\author{
Hélio Cândido da Silva, Vanessa Herrig, Maria de Lourdes L. Ferrarese and Osvaldo \\ Ferrarese-Filho* \\ Laboratory of Plant Biochemistry, Department of Biochemistry, University of Maringá, 87020-900 Maringá - PR, Brazil
}

\begin{abstract}
Depletion method was used to describe how soybean root consumed ferulic and p-hydroxybenzoic acids in nutrient culture. The results showed that excised cultured soybean roots consumed these allelochemicals very rapidly. At concentrations between 0.1 and $1.0 \mathrm{mM}$, roots consumed 50\% or more of ferulic acid after 6-h depletion. Although consumption started only after 3 h, similar behavior was verified with p-hydroxybenzoic acid.
\end{abstract}

Key words: Glycine max L. Merr., root, absorption, allelochemicals

\section{INTRODUCTION}

Higher plants produce a wide array of organic compounds, some of which have been reported as agents of plant-plant interactions, a phenomenon termed allelopathy (Rice, 1984). The magnitude of the impact of allelopathic compounds on plants depends on the type of compound, concentration and stability of that compound in the soil, and plant resistance and sensitivity to that compound. Among the types of chemical compounds identified as allelochemicals, cinnamic and benzoic acids derivatives, including ferulic and $p$ hydroxybenzoic acids, have frequently been mentioned in the literature (Einhellig, 1995). In soils, these compounds were found at concentrations between 0.01 and $0.1 \mathrm{mM}$ (Whitehead, 1964; Whitehead et al. 1982).

Exposure of plant roots to phenolic acids, at different concentrations, reduces water utilization (Hollapa and Blum, 1991), inhibits foliar expansion and root elongation (Blum and Rebbeck, 1989), reduces rates of photosynthesis (Patterson, 1981) and inhibits nutrient uptake (Lyu and Blum, 1990; Bergmark et al. 1992). Although information concerning the effects of ferulic and $p$-hydroxybenzoic acids on physiological responses of a variety of species is extensive, little attention has been given to the absorption of these compounds by roots.

Using root tips as a model system, we decided to investigate the consumption of ferulic acid, a cinnamic acid derivative, and of $p$-hydroxybenzoic acid, a benzoic acid derivative, by soybean in nutrient culture. The purpose of this investigation has how long-term objective to gain a better understanding of the allelopathic mechanism.

\section{MATERIALS AND METHODS}

General Procedures. Soybean seeds (Glycine $\max$ L. Merrill cv. BR16, Sealcoop Company, Maringá, Brazil) were soaked in a solution of $2 \%$ $(\mathrm{v} / \mathrm{v})$ sodium hypochlorite for two minutes and washed thoroughly with deionized water. The seeds were spread uniformly on paper towels, wrapped and transferred to plastic containers $(10 \mathrm{x}$ $16 \mathrm{~cm}$ ) with a small amount of deionized water at the bottom. The containers were incubated in a germination chamber (Tecnal TE 400, São Paulo, Brazil), in darkness. Air temperature was maintained at $25^{\circ} \mathrm{C}( \pm 0.2)$ and relative humidity ranged between 70 and $80 \%$.

After three-day imbibition, root tips $(<3 \mathrm{~cm}, 4 \mathrm{~g})$ were detached from cotyledons and transferred into continuously-aerated 0.5 -L containers. Each container was supplied with $200 \mathrm{ml}$ of nutrient solution prepared as described by Hoagland and Arnon (1950) containing $1 \mathrm{mM} \mathrm{KK_{2 }} \mathrm{PO}_{4}, 5 \mathrm{mM}$ $\mathrm{KNO}_{3}, 5 \mathrm{mM} \mathrm{Ca}\left(\mathrm{NO}_{3}\right), 2 \mathrm{mM} \mathrm{MgSO}{ }_{4}, 46 \mu \mathrm{M}$ $\mathrm{H}_{3} \mathrm{BO}_{3}, 9 \mu \mathrm{M} \mathrm{MnCl} 2,0.8 \mu \mathrm{M} \mathrm{ZnSO}_{4}, 0.3 \mu \mathrm{M}$ $\mathrm{CuSO}_{4}, 0.1 \mu \mathrm{M} \mathrm{H}_{2} \mathrm{MoO}_{4}, 70 \mu \mathrm{M}$ EDTA, $90 \mu \mathrm{M}$ $\mathrm{FeSO}_{4}$ and ferulic or $p$-hydroxybenzoic acids at different concentrations ( 0.1 to $1.0 \mathrm{mM})$. Nutrient solution was buffered with $17 \mathrm{mM}$ potassium phosphate and adjusted to $\mathrm{pH}$ 6.0. The containers were kept in the growth chamber, at $30^{\circ} \mathrm{C}$, in 
darkness. Experiments were made in aseptic conditions and during germination, fungal infection was absent from all samples tested. Ferulic and $p$-hydroxybenzoic acids used in this experiment were purchased from Sigma Chemical Company (St. Louis, Missouri, USA). All other reagents were of analytical grades.

Depletion Studies. Consumption of the phenolic acid per units of the root dry matter was based on the depletion of this compound from the initial 200 ml solution (Shann and Blum, 1987). Phenolic acid was determined by Folin-Ciocalteau method. Samples $(5.0 \mathrm{ml})$ of the nutrient solution or phenolic acid as standard were mixed with $0.75 \mathrm{ml}$ of $1.9 \mathrm{M} \mathrm{Na}_{2} \mathrm{CO}_{3}$ and $0.25 \mathrm{ml}$ of Folin-Ciocalteau phenol reagent. The mixture was allowed to stand in darkness at room temperature $\left(23^{\circ} \mathrm{C}-25^{\circ} \mathrm{C}\right)$ for one hour before its absorption was measured at $750 \mathrm{~nm}$ (Blum et al. 1991). Difference between the remaining acid at 3,6, 9, 12 and $24 \mathrm{~h}$ and its initial concentration in the nutrient solution determined the amount of consumed phenolic acid by the roots. After the last sampling, seedlings were removed, roots were detached, and placed in an oven for drying at $75^{\circ} \mathrm{C}$. After $24 \mathrm{~h}$, the roots were stored in a desiccator and dry matter determined immediately.

Data Analysis. Statistical analyses were carried out using the Sigmaplot ${ }^{\circledR}$ Scientific Graph System (Version 1.01, Jandel Scientific, USA, 1993). The results are given in the text as $\mathrm{p}$, the probability values. The criterion of significance adopted was $p$ $<0.05$. All values were expressed as means of three to five independent replicates \pm standard errors of the mean.

\section{RESULTS AND DISCUSSION}

Depletion studies of cinnamic and benzoic acid derivatives in nutrient solution were carried out to determine how soybean root tips in nutrient culture consume these allelochemicals. The choice of this method was based on the results shown by Shann and Blum (1987) who reported the ferulic acid uptake by cucumber roots. In the present work, soybean was chosen as the model plant because it produces a great primary root in a few days of germination and is sensitive to phenolic acids (Patterson, 1981). Root tips were chosen because they are not influenced by the photosynthesis or by reserve mobilization through the intact root.

To detect depletion of phenolic acids in nutrient culture, root tips were incubated with ferulic or $p$ hydroxybenzoic acids for $24 \mathrm{~h}$. Fig. 1 (upper panel) shows consumption of ferulic acid by roots over time. At all concentrations, consumption increased rapidly and linearly up to 6 to $12 \mathrm{~h}$, approximately. For example, at $0.1 \mathrm{mM}$, the consumed amount reached its maximum at $6 \mathrm{~h}(15$ mg g dry $\operatorname{root}^{-1}$ ) and then ceased completely. After $24 \mathrm{~h}$, all ferulic acid was consumed (17 mg g dry $\left.\operatorname{root}^{-1}\right)$. Above $0.1 \mathrm{mM}$ ferulic acid in the nutrient solution consumption showed a different behavior. At $0.5 \mathrm{mM}$, similar to the results with $0.1 \mathrm{mM}$, consumption by the roots increased linearly up to $6 \mathrm{~h}\left(33 \mathrm{mg} \mathrm{g}\right.$ dry root $\left.^{-1}\right)$ ceasing between 12 and 24 $\mathrm{h}\left(63 \mathrm{mg} \mathrm{g}\right.$ dry $\left.\operatorname{root}^{-1}\right)$. Yet, at $1.0 \mathrm{mM}$ consumption increased linearly up to $12 \mathrm{~h}(83 \mathrm{mg}$ $\mathrm{g}$ dry $\operatorname{root}^{-1}$ ) corresponding to $60 \%$ of the consumed amount after $24 \mathrm{~h}\left(137 \mathrm{mg} \mathrm{g}\right.$ dry root $\left.^{-1}\right)$. A discreet parabolic aspect could be observed after $12 \mathrm{~h}$ showing that the compound was available in the nutrient solution at the end of the experiment. In their experiments with cucumber, Shann and Blum (1987) reported that ferulic acid uptake was also very rapid over time. However, contrasting with the results of the present investigation, 0.1 $\mathrm{mM}$ ferulic acid uptake by cucumber increased in a hyperbolic manner, after 5-h depletion. On the other hand, according to the results of this investigation, $1.0 \mathrm{mM}$ ferulic acid consumption increased in a parabolic manner. However, comparison of these results is difficult since they were obtained with different species and results with cucumber were carried out with intact root. Anyhow, it was reasonable to accept that soybean root tips consumed ferulic acid very rapidly, at all concentrations. 

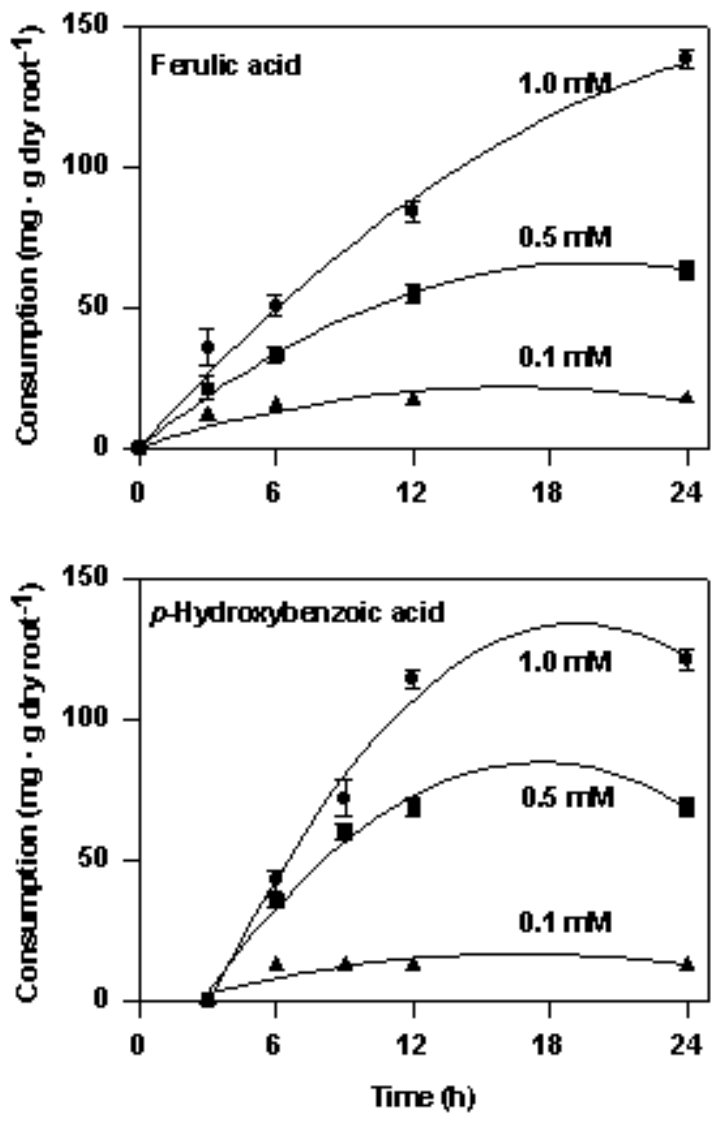

Figure 1 - Consumption of ferulic acid and $p$ hydroxybenzoic acids by soybean root tips calculated through analysis of solution over time.

Fig. 1 also shows consumption of $p$-hydroxybenzoic acid by root tips. Contrasting with the results obtained with ferulic acid, this allelochemical showed a different behavior over time. As revealed by the data, in the first $3 \mathrm{~h}$, roots did not consumed $p$-hydroxybenzoic acid and its absorption started only after this time. However, the results show that, similarly to ferulic acid, $p$ hydroxybenzoic acid was also consumed rapidly over time. At all concentrations, consumption was linear between 3 and $6 \mathrm{~h}$. Another important fact was that consumption of this allelochemical was rapid and reached similar values as those verified for ferulic acid within $6 \mathrm{~h}\left(13 \mathrm{mg}\right.$ g dry $\left.\operatorname{root}^{-1}\right)$. At $0.1 \mathrm{mM}$, all $p$-hydroxybenzoic acid of the nutrient solution was depleted. At the same time and at 0.5 $\mathrm{mM}, p$-hydroxybenzoic acid consumption was 33 mg g dry root ${ }^{-1}$ corresponding to an identical value observed with ferulic acid. In the same way, consumption of both compounds was identical after $12 \mathrm{~h}$ : $63 \mathrm{mg}$ of ferulic acid $\mathrm{g}$ dry $\operatorname{root}^{-1}$ and 67 mg of $p$-hydroxybenzoic acid g dry $\operatorname{root}^{-1}$. Finally, at $1.0 \mathrm{mM}$, it was clear that $p$-hydroxybenzoic acid was consumed more rapidly that ferulic acid, at least after $12 \mathrm{~h}: 114 \mathrm{mg} g$ dry $\operatorname{root}^{-1}$ for $p$ hydroxybenzoic acid and $83 \mathrm{mg}$ g dry $\operatorname{root}^{-1}$ for ferulic acid. Then, contrary to the results with ferulic acid, the curve shows an accentuated parabolic aspect with $p$-hydroxybenzoic acid indicating complete depletion of this compound in the solution. After $12 \mathrm{~h}$, roots consumed $95 \%$ of this allelochemical.

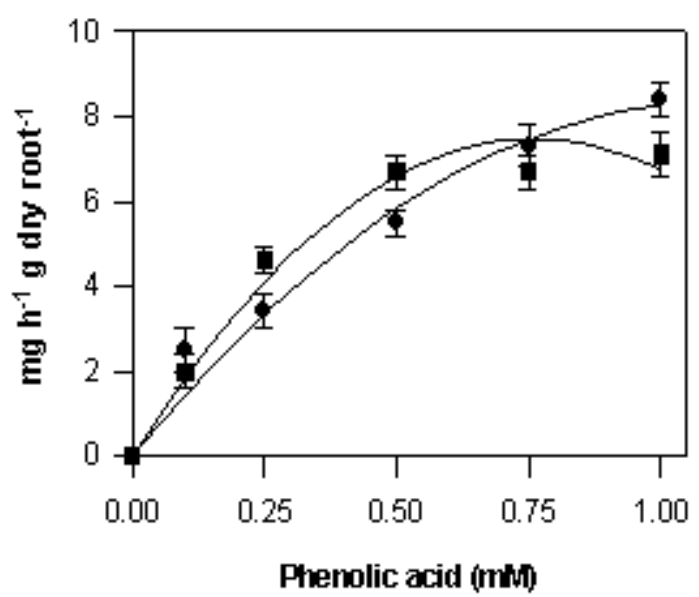

Figure 2 - Consumption rates of ferulic acid $(\bullet)$ and $p$-hydroxybenzoic acid ( $\boldsymbol{\square})$ against concentration in nutrient culture after $6 \mathrm{~h}$ depletion.

In order to investigate consumption of both phenolic acids against concentration in the nutrient solution, root tips were incubated with ferulic or $p$ hydroxybenzoic acid for 6 h. As shown in Fig. 1, $35 \%$ to $50 \%$ of the allelochemicals were depleted in the nutrient solution. Fig. 2 illustrates the results obtained at concentrations between $0.1 \mathrm{mM}$ and $1.0 \mathrm{mM}$. As can be seen, the data obtained showed that consumption of both compounds was linear up to $0.25 \mathrm{mM}$, approximately. At $0.5 \mathrm{mM}$, consumption rates were $6.7 \mathrm{mg} \mathrm{h}^{-1} \mathrm{~g}$ dry root $^{-1}$ for $p$-hydroxybenzoic acid and $5.5 \mathrm{mg} \mathrm{h}^{-1} \mathrm{~g}$ dry root ${ }^{-1}$ for ferulic acid. On the other hand, at $1.0 \mathrm{mM}$, concentration rates were $7.8 \mathrm{mg} \mathrm{h}^{-1} \mathrm{~g}_{\text {dry }}$ root $^{-1}$ to $p$-hydroxybenzoic acid and $8.4 \mathrm{mg} \mathrm{h}^{-1} \mathrm{~g} \mathrm{dry} \mathrm{root}^{-1}$ for ferulic acid. Analyzing Fig. 2, it is possible to verify that consumption of $p$-hydroxybenzoic acid reached its maximum at $0.5 \mathrm{mM}$ while the consumption of ferulic acid increases continuously after $1.0 \mathrm{mM}$. Although this observation showed some apparent differences between these two compounds, statistical analysis (paired t-test of the 
curves) was not significant $(\mathrm{p}=0.94)$. As a summing up it may be stated, that both allelochemicals were consumed in similar manner by root tips. With intact root of cucumber, Shann and Blum (1987) observed that ferulic acid uptake was more rapid than $p$-hydroxybenzoic acid, after 5-h depletion.

In conclusion, the results of the present investigation showed that both ferulic and $p$ hydroxybenzoic acids were taken up at higher rates in nutrient culture indicating absorption by roots. The underlying physiological mechanisms, however, are poorly understood. Although the experiments shown in this investigation have been carried out under aseptic conditions, it was possible that microbial or physicochemical breakdown products in nutrient culture have led to overestimate consumption results by roots. In their experiments with cucumber root, Blum et al. (1985) reported that microbial metabolic products of ferulic acid were detected in the nutrient solution suggesting that some of these products might have been consumed by root. To eliminate this interference, parallel analysis of the investigated phenolic acids in soybean root tissues could be of great value. Preliminary results showed that soybean intact roots metabolized ferulic acid after 12-h depletion (unpublished data). Metabolic products of ferulic acid in root tissues were detected by GC-MS method and their quantification is still in progress.

\section{RESUMO}

A técnica de depleção foi usada para determinar como raízes de soja consomem os ácidos ferúlico e $p$ hidroxibenzóico em solução nutritiva. Os resultados mostraram que extremidades excisadas de raízes de soja consumiram rapidamente estes aleloquímicos. Entre concentrações de 0,1 e 1,0 mM , 50\% ou mais de ácido ferúlico foi consumido após $6 \mathrm{~h}$ de depleção. Embora o consumo tenha iniciado somente após $3 \mathrm{~h}$, comportamento idêntico foi encontrado com ácido $p$ hidroxibenzóico.

\section{REFERENCES}

Bergmark C.; Jackson W.A.; Volk R.J. \& Blum U. (1992), Differential inhibition by ferulic acid of nitrate ammonium uptake in Zea mays L. Plant Physiol., 98, 639-645

Blum, U.; Dalton, B.R. \& Shann, J.R. (1985), Effects of various mixtures of ferulic acid and some of its microbial metabolic products on cucumber leaf expansion and dry matter in nutrient culture. J. Chem. Ecol., 11, 619-641

Blum, U. \& Rebbeck, J. (1989), Inhibition and recovery of cucumber roots given multiple treatments of ferulic acid in nutrient culture. J. Chem. Ecol., 15, 917-928

Blum, U.; Wentworth, T.R.; Klein, K.; Worsham, A.D.; Kimg, L.D.; Gerig, T.M. \& Lyu, S.W. (1991), Phenolic acid content of soils from wheat-no till, wheat-conventional till, and fallow-conventional till soybean cropping systems. J. Chem . Ecol., 17, 10451068

Einhellig F.A. (1995), Allelopathy: current status and future goals. In: Allelopathy. Organisms, Processes and Applications. ACS Simposium, Washington, ed. Inderjit; K.M.M.; Dakshimi \& F.A. Einhellig. American Chemical Societies, Series 582, New York. pp. 1-24

Hoagland, D.R. \& Arnon, D.I. (1950), The waterculture method of growing plants without soil. Calif. Agric. Exp. Stat. Cir., 347

Holappa L.D. \& Blum U. (1991), Effects of exogenously applied ferulic acid, a potential allelopathic compound. On leaf growth, water utilization, and endogenous abscisic acid levels of tomato, cucumber, and bean. J. Chem. Ecol., 17, 865-886

Lyu S.W. \& Blum U. (1990), Effects of ferulic acid, an allelopathic compound, on net $\mathrm{P}, \mathrm{K}$, and water uptake by cucumber seedlings in a 7 split-root system. $J$. Chem. Ecol., 16, 2429-2439

Patterson D.T. (1981), Effects of allelopathy chemicals on growth and physiological responses of soybean (Glycine max). Weed Sci., 29, 53-59

Rice, E.L. (1984), Allelopathy. Academic Press. New York

Shann, J.R. \& Blum, U. (1987), The uptake of ferulic acid and $p$-hydroxybenzoic acids by Cucumis sativus. Phytochem., 26, 2959-2964

Whitehead, D.C. (1964), Identification of $p$ hydroxybenzoic, vanillic, $p$-coumaric, and ferulic acids in soils. Nature (London). 202, 417-418

Whitehead, D.C.; Dibb, H. \& Hartley, R.D. (1982), Phenolic compounds in soil as influenced by the growth of different plant species. J. Appl. Ecol., 19, $579-588$ 